\title{
Candida esophagitis complicated by esophageal stricture
}

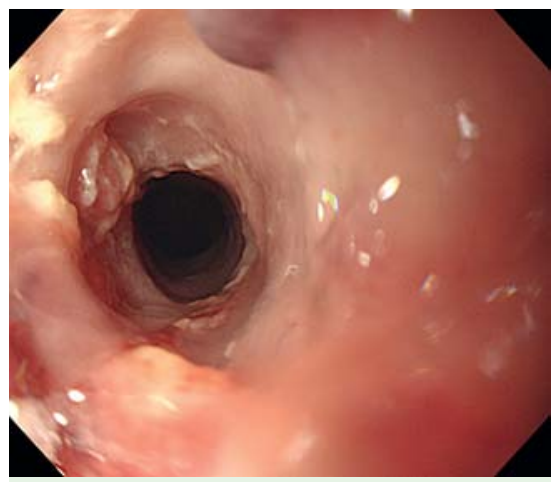

Fig. 1 Esophageal luminal narrowing was observed at $23 \mathrm{~cm}$ from the central incisor with irregular mucosa and multiple whitish exudates, through which the scope (GIF-H260, Olympus, Japan) could not pass.

A 31-year-old woman was referred to the department of gastroenterology with dysphagia accompanied by odynophagia without weight loss. The patient was immunocompetent and her only medication was synthyroid, which she had been taking for the past 15 years due to hypothyroidism. The patient said that she had her first recurrent episodes of odynophagia 7 years previously and recalled that endoscopic examination at that time had revealed severe candida esophagitis. Her symptoms improved after taking medication for 1 month. She was without symptoms for a couple of years, but about 5 years prior to the current presentation, she began to experience dysphagia from time to time when taking pills or swallowing meat, and these episodes had become more frequent and had worsened during the past year. The patient visited a gastroenterologist and underwent endoscopy, which revealed narrowing of the esophagus and whitish plaques scattered throughout the mucosa.

The endoscopy performed at our hospital also revealed esophageal luminal narrowing at $23 \mathrm{~cm}$ from the central incisor, with irregular mucosa and multiple ulcers and whitish exudates ( $\bullet$ Fig. $\mathbf{1}$ ). The scope (GIF-H260, Olympus, Japan) could not pass beyond the stricture. Multiple biopsies were taken and revealed fungal infection, consistent with candidiasis, with ul-

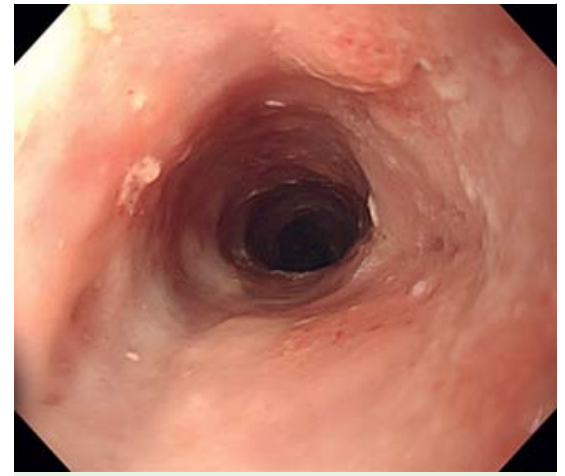

Fig. 2 Follow-up endoscopy performed 6 weeks after the initial evaluation at our hospital showed improvement of inflammation, but still the narrowed lumen did not allow the passage of the endoscope.

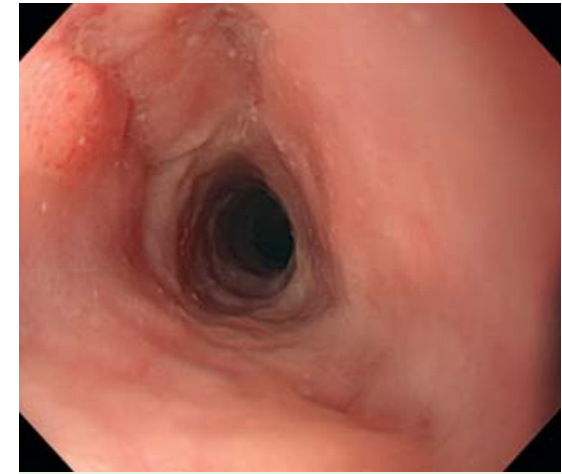

Fig. 3 Follow-up endoscopy for the evaluation of dysphagia 3 months after the initiation of treatment with a antifungal agent revealed further stenosed lumen, through which not even the GIF-Q260, an endoscope of smaller caliber than the GIF-H260, could pass.

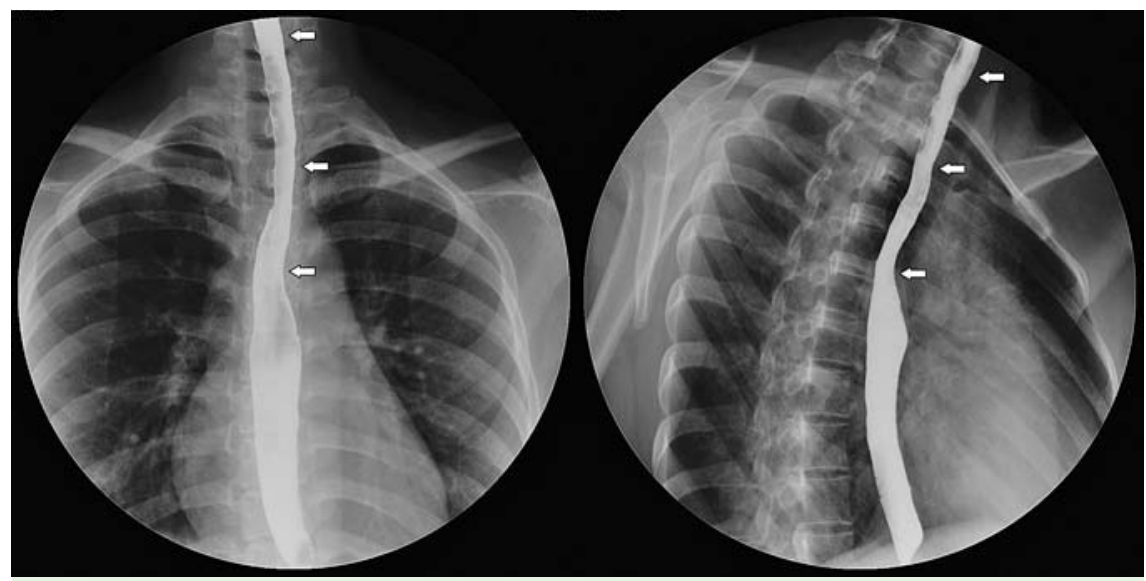

Fig. 4 Barium esophagogram demonstrated narrowing of the upper and mid-esophagus (arrows) with unaffected distal esophagus.

cer and pseudoepitheliomatous hyperplasia. The patient was prescribed fluconazole and at follow-up endoscopy 6 weeks later the esophageal stenosis and mucosal lesion had improved. However, the lumen was still not wide enough for the GIFH260 to pass and only the GIF-Q260, which has a smaller caliber, could pass through the stricture site ( $\bullet$ Fig. 2).

During the follow-up at the outpatient department, endoscopy was performed again because the patient complained of gradual worsening of dysphagia with solid foods. Endoscopic examination showed more stenotic lumen through which even the GIF-Q260 could not pass ( $\bullet$ Fig. 3 ). Barium esophagogram demonstrated narrowing deformity with an irregular base in the upper and mid-esophagus; the distal esophagus was normal ( $\mathbf{F i g}$. 4).

Our case demonstrates the importance of proper and timely management of candida esophagitis, as inadequate and delayed treatment can result in esophageal stricture that can become debilitating.

\section{Competing interests: None}

Endoscopy_UCTN_Code_CCL_1AB_2AC_3AZ 
J. J. Hyun, H. J. Chun, B. Keum, Y. S. Seo, Y. S. Kim, Y. T. Jeen, H. S. Lee, S. H. Um,

C. D. Kim, H. S. Ryu

Department of Internal Medicine, Institute of Digestive Disease and Nutrition, Korea University College of Medicine, Seoul, Korea

\section{Bibliography}

DOI $10.1055 / \mathrm{s}-0029-1244014$

Endoscopy 2010; 42: E180 -E181

(C) Georg Thieme Verlag KG Stuttgart · New York . ISSN 0013-726X
Corresponding author

H. J. Chun, MD, PhD

Department of Internal Medicine Institute of Digestive Disease and Nutrition Korea University College of Medicine

126-1, Anam-dong

5-Ga, Seongbuk-Gu

Seoul

Korea 136-705

Fax: +82-2-9531943

drchunhj@chol.com 